\title{
Changes in the portal and splenic veins in portal hypertension and their relation to splenomegaly ${ }^{1}$
}

\author{
JOHN B. WILSON \\ From the Department of Pathology, University of Edinburgh
}

SYNOPSIS This paper is a pathological study on the portal veins demonstrating that the changes in the portal circulation and in the spleen reflect the degree or duration of portal hypertension.

Cirrhosis of the liver has been known for many years to be accompanied by changes in the portal venous system and the spleen, and they were thought to be secondary to the congestion brought about by the distortion of the lobular pattern in the liver; somewhat similar changes occur in the absence of cirrhosis of the liver when the portal or splenic veins are blocked. The congestion gives rise to an increase in pressure in the vein (portal hypertension) and the development of a collateral circulation. Banti (1898) described the changes in the portal vein as a phlebosclerosis, and later Pei-Lin Li (1940), studying the pathological changes in the vein wall in greater detail, considered that the medial hypertrophy and intimal thickening were due to an increase in pressure in the vein.

In the hope that examination of the portal and splenic veins would give some indication as to the extent or duration of the congestion, portions of these veins were obtained from cases with cirrhosis of the liver and portal congestion with splenomegaly, then carefully studied. The pathological changes in them were noted and correlated with the other lesions, including the size of the spleen. A liver was taken to be cirrhotic if the following changes were seen: 1 , Obvious nodularity, 2 , an excess of fibrous tissue throughout, and 3, marked distortion of the lobular architecture.

MATERIAL AND METHODS

Sections of the portal and splenic veins were examined from 30 cases of cirrhosis of the liver, and from the splenic vein in seven cases in which splenectomy had been performed for recurrent haematemeses or splenomegaly. One of the latter subsequently came to necropsy so that in it the portal vein also was available for study. The microscopic appearance of the portal and splenic

'Part of a thesis accepted for the degree of Doctor of Medicine by the University of Edinburgh. veins in two control cases was found to be similar to that noted in the two cases included in the series, in which no pathological changes had occurred and to the description of the normal histology of the veins given by Pei-Lin Li (1940), Maximow and Bloom (1948), Brash and Jamieson (1937), and Brendle (1950).

So far as possible the sections of the portal vein were taken from a point midway between its origin and bifurcation. Sections of the splenic vein were taken from a point midway in its course along the posterior aspect of the pancreas. In the material obtained at operation the only portion of the splenic vein available was the proximal centimetre as it left the spleen.

Transverse sections were stained using, 1 , haematoxylin (Meyer's) and eosin; 2, Weigert's elastic tissue stain counterstained with van Gieson's connective tissue stain; 3, Heidenhain's azan.

\section{CHANGES IN PORTAL VEIN}

GROUP I: NORMAL PORTAL VEIN Two cases were studied (Fig. 1). The endothelium lining the vein was not always clearly seen but it appeared to be applied directly to the innermost layer of the internal elastic lamina, no subendothelial layer being visible. The elastic tissue of the media ran transversely between the muscle cells in long, thin, wavy strands, the internal elastic lamina being the thickest and best defined. The rest of the media was formed by a compact layer of circular muscle fibres two to four bundles thick and separated from each other by a few loose strands of connective tissue. External to the media and separated from it by a few more connective tissue cells was a loosely formed adventitia composed of two to three small bundles of longitudinally-arranged muscle cells. Between these muscle bundles, running mainly in a longitudinal direction, there was loose connective tissue and a few scattered elastic tissue fibres. External to this again was more loose connective tissue which contained nerve bundles and small blood vessels. 
GROUP II: SLIGHT HYPERTROPHY OF MUSCULAR AND ELASTIC TISSUE COATS Eleven cases were studied. There was an increase in the thickness of the vein wall because of slight hypertrophy of all its coats. This increase in thickness is well brought out by comparison of Fig. 1 with Fig. 2. Portions of the vein wall showed no intimal thickening but in other parts there was slight patchy intimal thickening due to the development of small muscle cells in the subendothelial layer. These cells were cut transversely and occurred in small groups with a few thin scattered strands of elastic tissue between the cells. The internal elastic lamina was slightly thickened and stood out more clearly than in the normal vein, while the elastic tissue fibres in the media were also increased in size though not apparently in number. Both the media and adventitial muscle cells were slightly hypertrophied.

GROUP III: MORE MARKED HYPERTROPHY OF MUSCULAR COATS In this group of 15 cases there was definite thickening of the vein wall due to changes in all coats. The intima was diffusely increased in depth and through it were scattered small muscle cells, usually cut transversely, around which ran many thin fibres of elastic tissue, mainly in a circular direction. Through the intima ran many small strands of collagen. The superficial portion of the intima was a homogeneous pale colour and in the lumen of the vein small numbers of red corpuscles were observed adherent to the vein wall, sometimes with a covering of endothelium over them.

The internal elastic lamina was prominent and throughout the media were very many short, thick elastic tissue fibres, cut both longitudinally and transversely. The medial muscles, as well as showing slight hypertrophy, were increased in number so that the media was now six to eight muscle bundles thick.

The adventitial muscles were also slightly hypertrophied, the muscle bundles being larger and more closely arranged than in the normal vessel. Though there was no increase in the number of muscle bundles in the adventitia, the muscle cells were increased both in number and in size. There was no obvious increase in the amount of elastic tissue in the adventitia.

GROUP IV: WELL-MARKED INTIMAL THROMBOSIS IMPOSED ON CHANGES NOTED IN GROUP III The mOSt prominent feature in these three cases was the presence of a large, recently formed thrombus (Fig. 4) on an already eccentrically thickened intima, eccentrically thickened presumably because of previous thrombotic episodes, for it was composed of dense collagenous tissues and the recently formed more superficial thrombus was undergoing organiza-

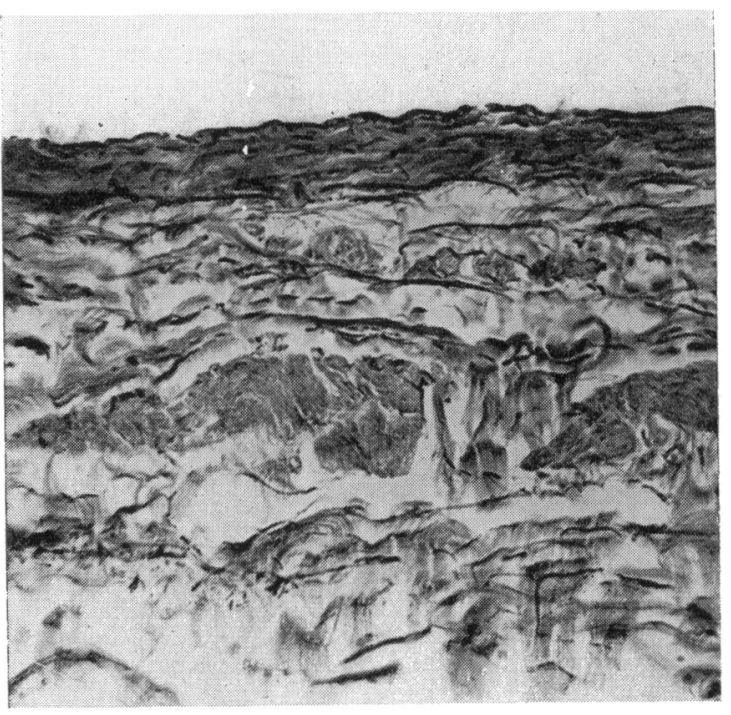

FIG. 1. A normal portal vein. (Weigert and van Gieson. $\times 220$.

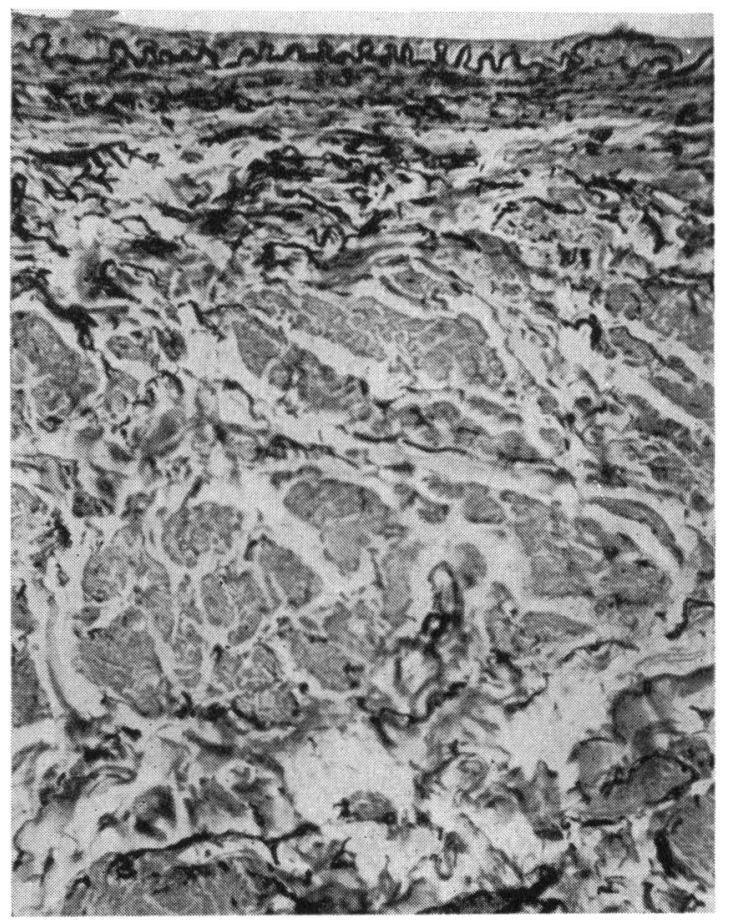

FIG. 2. Portal vein, group II, showing slight hypertrophy of the muscular and elastic tissue coats with minimal intimal changes. (Weigert and van Gieson. $\times 220$.) 
tion by active looking fibroblasts. In the deeper portion of the thickened intima there were many well-formed vascular spaces, and internal to this again many small elastic tissue fibres had proliferated from the neighbouring internal elastic lamina.

The internal elastic lamina was not easily distinguished, for the media was largely replaced by a dense aggregation of elastic tissue amongst which only a few muscle cells remained. External to the media the adventitia consisted of markedly hypertrophied bundles of longitudinal muscle cells cut slightly obliquely.

There was considerable variation in the cases which fell into group IV.

Case 1 There was extensive intimal thickening with recent thrombosis. The adventitia was poorly defined and could scarcely be distinguished, while the most notable feature of the section was the well-marked vascularity of the depths of the intima which contained numerous endothelial-lined vascular spaces and in one part a small arteriole (Fig. 5).

Case 2 The reduplication and fragmentation of the elastic tissue into the deepest portion of the intima was very marked, though the proliferation of elastic tissue in the media was not such a feature as in the two previous cases. In the intima there were one or two small areas of degeneration into which haemorrhage had occurred. The medial and adventitial muscles and the medial elastic tissues were hypertrophied throughout the whole circumference of the vessel.

\section{SPLENIC VEIN}

The changes seen at necropsy were of a similar nature but of a slightly less degree than those seen in the portal vein of the same case.

The change seen in biopsies of these veins showed certain characteristics. The adventitial muscle was poorly formed and showed little hypertrophy, while the changes in the medial muscle were more definite but still slight. Intimal changes were, however, present in most cases and there was intimal thickening due to hypertrophy of the same elements as made up the increase in depth in the portal veins and the proximal end of the splenic vein. In two cases the thickening was sharply localized to form raised plaques which projected into the lumen of the vessel (Fig. 6). The changes were similar to those noted and illustrated as occurring in this portion of the vein by McMichael (1935).
RELATIONSHIP BETWEEN CHANGES IN PORTAL AND SPLENIC VEINS AND SIZE OF THE SPLEEN

After the portal and splenic veins had been examined and classified, the changes observed in them were correlated with the size of the spleen (Table I).

TABLE I

\begin{tabular}{ccccc} 
& \multicolumn{5}{l}{ Changes in the Portal Vein } \\
\cline { 2 - 5 } Weight of Spleen (g.) & Group I & Group II & Group III & Group IV \\
\hline $0-199$ & 2 & 3 & 1 & - \\
$200-399$ & - & 6 & 7 & 1 \\
$400-599$ & - & 1 & 7 & -1 \\
$600-799$ & - & - & - & 1 \\
800 & - & 1 & -15 & 3
\end{tabular}

Finally the pathological changes in the portal veins were correlated with the presence of oesophageal veins and a clinical history of haematemesis (Table II).

\section{DISCUSSION}

The association of cirrhosis of the liver, phlebosclerosis of the portal and splenic veins, and splenomegaly was noted by Banti in 1898 . He thought that the primary pathological process was in the spleen and that a toxic factor spread thence along the splenic and portal veins to the liver. However, the changes noted by Banti in the spleen have not been described without liver disease (McMichael, 1934) or obstruction in the portal or splenic veins (Kelsey, Robertson, and Giffin, 1947). McMichael described the changes in the veins as hypertrophy of the muscle coats with intimal fibrosis. Subsequently Pei-Lin Li (1940) compared and contrasted the changes in the portal and splenic veins in cases of cirrhosis of the liver with those found in the inferior vena cava under conditions of increased intravenous pressure. He noted that hypertrophy of the medial muscle of the portal vein was often succeeded by intimal changes with the development of small muscle bundles arranged longitudinally in the subendothelial layer, and considered that it was replacement of these muscles by fibrous tissue which produced the thickened and fibrosed intima in some cases. He could find no evidence of any degenerative or

TABLE II

\begin{tabular}{|c|c|c|c|c|c|c|c|c|c|c|c|c|c|c|c|c|c|c|}
\hline Case no. & 1 & 2 & 3 & 5 & 8 & 13 & 15 & 16 & 17 & 18 & 19 & 20 & 21 & 23 & 24 & 25 & 26 & 31 \\
\hline Varicose veins & + & + & + & - & - & + & - & + & - & + & + & + & - & - & + & - & + & + \\
\hline Haematemesis & - & + & - & - & - & + & - & + & - & - & + & - & - & - & + & - & - & - \\
\hline Vein changes & IV & IV & III & III & III & III & III & III & III & III & III & III & III & III & IV & III & III & III \\
\hline
\end{tabular}




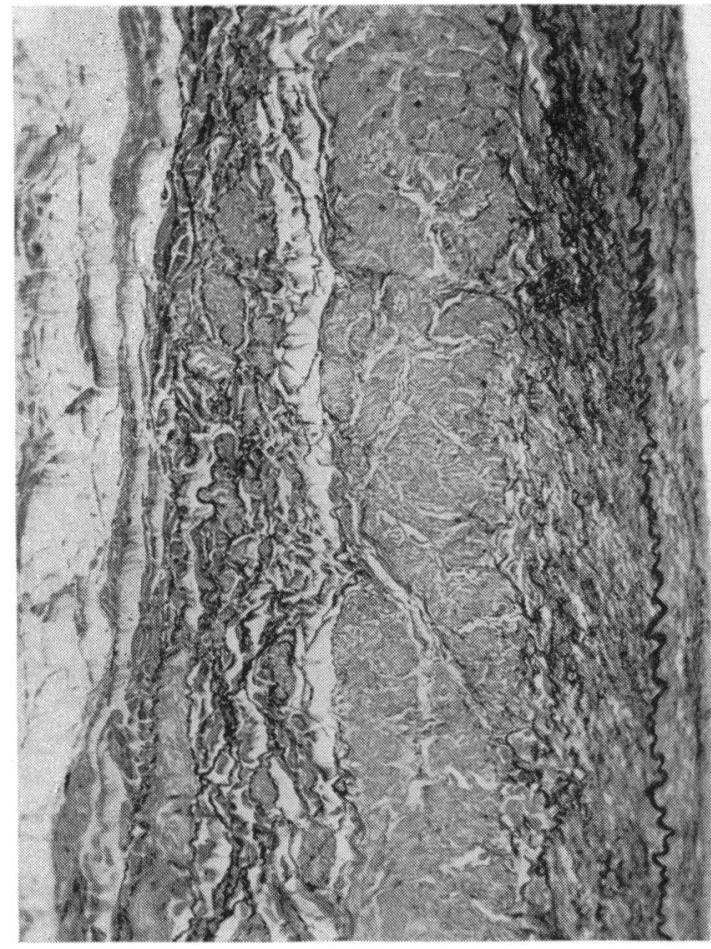

FIG. 3

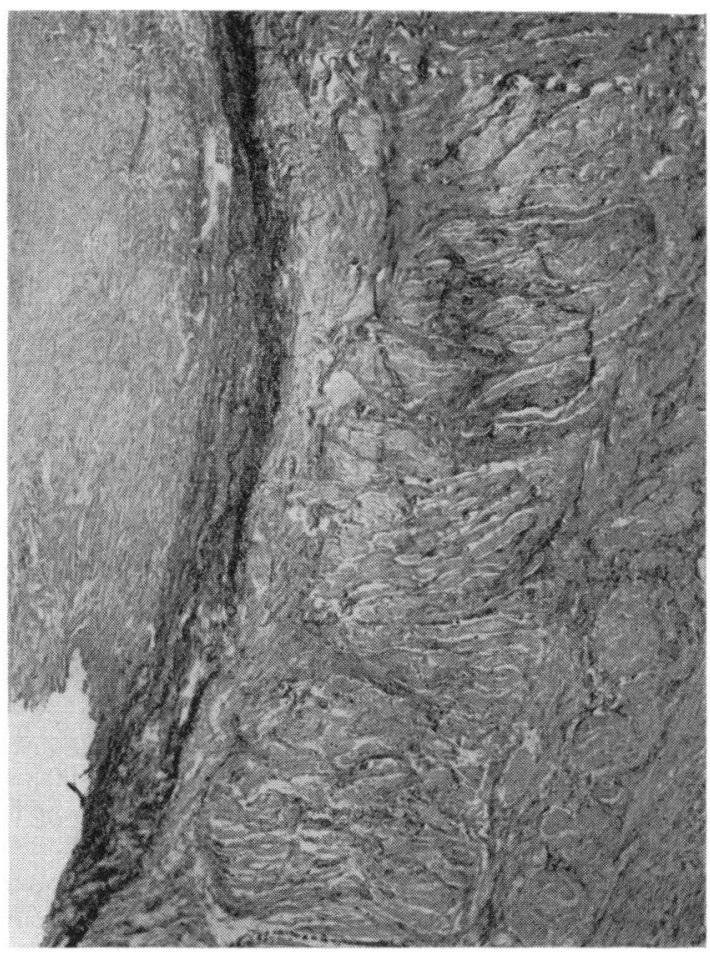

FIG. 4

FIG. 3. Portal vein, group III, with more marked hypertrophy of the muscular coats and definite, usually diffuse, intimal thickening. (Weigert and van Gieson. $\times 80$.)

FIG. 4. Portal vein, group IV, showing well-marked intimal thrombosis superimposed on the changes noted in group III. (Weigert and van Gieson. $\times 15$.

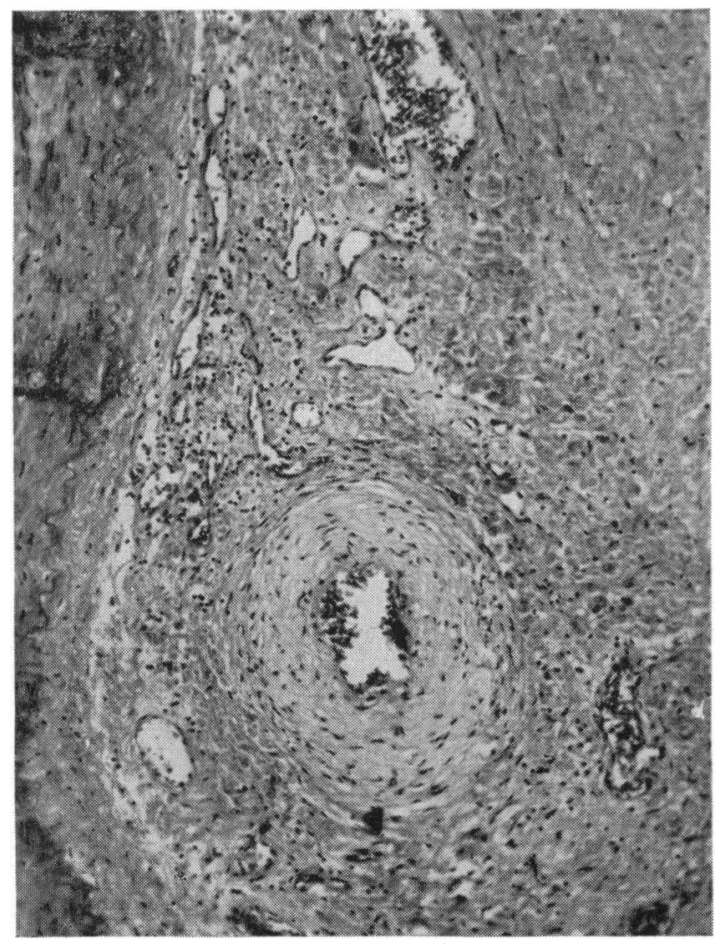

FIG. 5

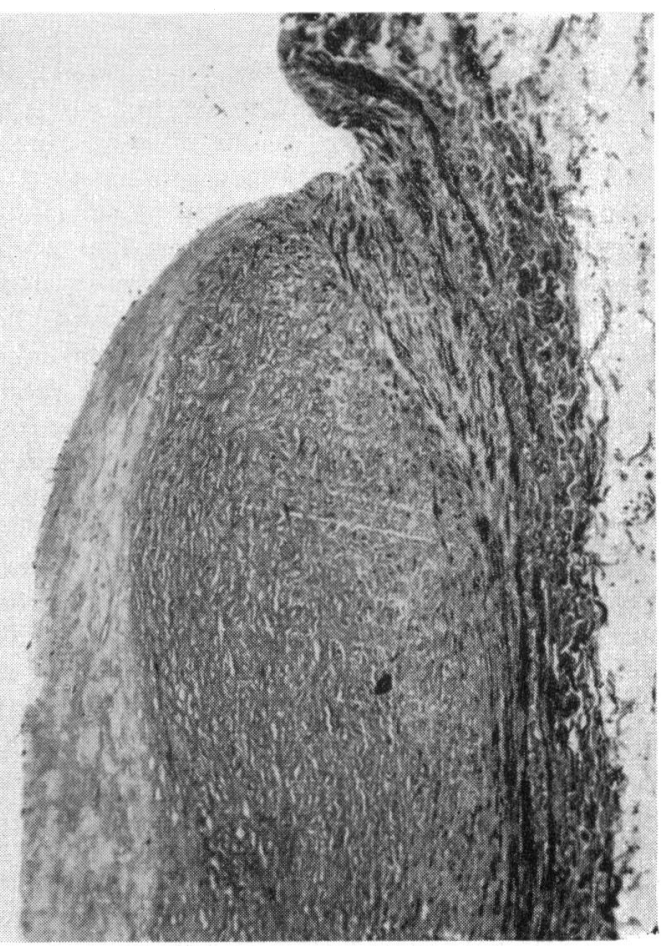

FIG. 6

FIG. 5. Vascularization of the deep portions of the thrombus adjacent to the internal elastic lamina. (Haematoxylin and eosin $\times 80$.)

FIG. 6. Localized thickening of the splenic vein $($ Azan. $\times 80$. 
atheromatous change. Since veins were found with hypertrophy of the medial muscle and no intimal thickening but never intimal hypertrophy without medial muscle hypertrophy, it was assumed that the change in the medial muscle preceded that in the intima. The changes too in the splenic vein were always of a slighter degree than those in the portal vein of the same case and comparison of the lesions in these two vessels afforded further support for his contention.

These findings have been confirmed. In contradistinction, however, to Pei-Lin Li's conclusion that where there is an increased venous pressure the hypertrophy of the adventitial muscle could not be regarded as significant, the degrees of hypertrophy in the medial and adventitial muscle coats were always noted to be equal. Accurate measurement of the adventitia was difficult, for its boundaries were often ill defined and the whole loosely arranged. However, since the hypertrophy of the muscle bundles occurred at the expense of the loose connective tissues rather than by any increase in width of the coat as a whole (Figs. 1, 2, and 3), the measurement of the width of the coat as carried out by Pei-Lin Li was not considered a satisfactory index of its muscular hypertrophy.

Furthermore, the changes in the elastic tissue of the media were noted to be of roughly the same extent as the accompanying hypertrophy of the medial muscles, this increase in the amount of elastic tissue and an increasingly well-defined internal lamina being often the first and most easily observed change in these veins (Fig. 2). Where the elastic tissue changes were most marked, amounting to an elastosis of the media (Fig. 4), the factor responsible for these lesions had probably produced its greatest effect. The most marked elastic tissue changes in the media were noted where there was extensive intimal thrombosis, suggesting that the thrombosis too was a result of this same factor, probably prolonged and excessive pressure in the vein. However, the occurrence of thrombosis in a vein depends on so many factors (Rosenthal, 1925; Evans, 1929; Simonds, 1936; Reich, 1942), and the fact that the muscular hypertrophy was sometimes most marked below the greatest intimal thickening, combine to make it difficult to decide the relative importance of these findings. In spite of this, and since in the cases with intimal thrombosis the muscle coats and elastic tissue were also markedly hypertrophied, it seems reasonable to suggest that these changes are the result of prolonged congestion. The four groups of venous changes described probably do represent successive stages of a process in the vein wall, the hypertrophy of the internal elastic lamina and the medial muscle being followed by further hypertrophy of both medial and adventitial muscle and elastic tissue with an increase in depth of the subendothelial layer, patchy at first and later becoming more diffuse. A third stage in the process has been reached in those cases in which the hypertrophy of these coats is most marked. Extensive intimal thrombosis is probably a terminal occurrencein thischain of events.

These changes were at one time thought to be due to a weakening of the vein wall by inflammation (Fischer, 1900; Warthin, 1910; Faber, 1912), while Simmonds (1912) distinguished a group in which syphilis was thought to be important. However, no evidence of inflammation was found in any of the cases examined. A further cause of these changes has been suggested as being a lack of nutritional factors with subsequent weakening of the vein wall. However, similar changes are found in veins in which there is a definite increase in pressure, for instance, in arteriovenous aneurysms (Hermannes, 1923), and in 11 of the 31 cases examined a collateral circulation had developed around the oesophagus, a finding which McMichael (1934) considered definite proof of an increased pressure in the portal vein, its presence during life making a clinical diagnosis of portal hypertension possible (Reynell, 1951).

If, as has been suggested, the presence of varicose veins around the oesophagus denotes an increased pressure in the portal vein and the changes noted in the veins examined are due to that increased pressure, then the most marked changes in the veins should be associated with oesophageal varices. Examination of the findings from the material does bear this out (Table II), thus adding further support to the contention that the changes in group IV occur after those in group III.

Some light was also thrown on the aetiology of the intimal thickening. In 10 of the cases examined red blood cells were seen firmly adherent to the vein wall, and in one or two cases endothelium had grown over them. In the three cases belonging to group IV, the thrombus appeared to be superimposed on a previous older lesion, for muscle cells and elastic tissue were not present in the eccentrically thickened portion of the intima. The mechanism whereby these intimal changes arise may be analogous to that described by Duguid (1946) in the formation of atheromatous thickening in the walls of arteries where thrombosis and subsequent overgrowth of endothelium also occurs. Providing additional support for this contention are the facts that where the intimal thickening was still of small amount, the increase in depth was caused by hypertrophy of all elements (group III), but where the thickening was more marked, that is in group IV, the intimal thickening was eccentric 
and was formed of fibrous tissue with, in its depths, many small endothelial-lined vascular channels and in one case a small, well-formed arteriole (Fig. 5). This marked vascularity of the depths of the intima probably accounts for the infrequency with which degenerative intimal changes were noted, though in Case 2 small areas of necrosis were seen in the thickened intima and the calcification in two cases was presumably the result of a similar process in a part of the vein where the thrombus was deepest.

If the extent of the splenomegaly associated with cirrhosis of the liver depends only on the extent or duration of the increased portal vein pressure, the changes in the vein wall will show a direct relationship to the size of the spleen. Study of the portal veins examined in this investigation should therefore enable a decision to be reached as to the relative importance of congestion and hyperplasia (Table I).

Table I includes two cases in which the changes were so different as to deserve separate consideration. In the first (male, aged 47) the splenic pulp showed no hyperplasia at all, the spleen weighing $40 \mathrm{~g}$. and being noted as showing atrophy, yet group III changes were present in the portal vein, while in the second (male, aged 75) only slight changes (group II) were present in the portal vein yet there was marked hyperplasia of the splenic pulp (weight 970 g.) without fibrosis or any other evidence of congestion. Probably the factor which caused the liver damage in the latter case, perhaps not long before death, had at the same time affected the spleen (cf. Menon, 1938). However, apart from these two cases there is a definite relationship between the changes in the portal vein and in the spleen. It appears therefore that the extent of the splenomegaly which occurs in cirrhosis of the liver is usually related to the extent of the changes in the portal vein, though other factors play an unknown and presumably variable part: in other words, the same factor which causes the changes in the veins is responsible for part of the splenomegaly. Whether this factor is the degree or duration of the rise in portal pressure is difficult to ascertain, but the size of the spleens and the respective ages of the two cases commented on above suggest that the age is not an important factor in deciding the extent of the splenomegaly.

\section{SUMMARY}

The portal and splenic veins in 31 cases of cirrhosis of the liver were examined and the changes occurring in them classified into four main groups. These groups and the different stages of their production were considered to give an indication as to the degree or duration of the congestion, a finding supported by the relationship between these changes and the presence of a collateral circulation.

In the group with the most marked changes in the vein walls, thrombosis was a feature.

Furthermore, there was a relationship between the different changes in the portal and splenic veins and the size of the spleen in portal hypertension. The more marked the changes in the veins, the larger the spleen. The conclusion is therefore reached that the changes in the veins and in the spleen in cases of portal hypertension reflect the degree of duration of that increase in portal pressure.

The material for this investigation was obtained from the Pathology Department of the Royal Infirmary, Edinburgh, and Edinburgh University. I have to thank Professor A. M. Drennan and Dr. R. F. Ogilvie for their kind encouragement and help and also Sir James Learmonth for access to much interesting case material. The photomicrographs are the work of Mr. T. C. Dodds.

\section{REFERENCES}

Banti, G. (1898). Splenomegalie mit Lebercirrhose. Beitr. path. Anat., 24, 21-33.

Brash, J. C., and Jamieson, E. B. (1937). Cunningham's Text-book of Anatomy, 7th ed. Oxford University Press, London.

Brendle, E. (1950). Uber den Bau der menschlichen Pfortader und ihrer Wurzeln. Acta anat. (Basel), 10, 108-129.

Duguid, J. B. (1946). Thrombosis as a factor in the pathogenesis of coronary atherosclerosis. J. Path. Bact., 58, 207-212.

Evans, W. H. (1929). The blood-platelets in splenic anaemia, with special reference to treatment by splenectomy. Lancet, 1, 1, 277-282.

Faber, A. (1912). Die Arteriosklerose: ihre pathologische Anatomie, ihre Pathogenese und Aetiologie, p. 122. Fisches, Jena.

Fischer, B. (1900). Ueber Entzündung, Sklerose und Erweiterung der Venen mit besonderer Berücksichtigung des elastischen Gewebes der Gefässwand. Beitr. path. Anat., 27, 494-554.

Hermannes, P. (1923). Zur Frage der arterialisierten Venen beim arterio-venösen Aneurysma. Beitr. path Chir., 130, 40-59.

Kelsey, M. P., Robertson, H. E., and Giffin, H. Z. (1947). The rôle of chronic thrombosis of the portal vein and its tributaries in the syndrome of splenic anaemia. Surg. Gynec. Obstet., 85, 289-293.

Li, Pei-Lin (1940). Adaptation in veins to increased intravenous pressure, with special reference to the portal system and inferior vena cava. J. Path. Bact., 50, 121-136.

McMichael, J. (1934). The pathology of hepatolienal fibrosis. Ibid., 39, 481-502.

_. (1935). Splenic anaemia. Trans. med.-chir. Soc. Edinb., 1934-35, 97-116.

Maximow, A. A., and Bloom, W. (1948). Textbook of Histology, 5th ed. W. B. Saunders, Philadelphia and London.

Menon, T. B. (1938). The splenic reaction in experimental cirrhosis and in pre-cirrhotic intoxication. J. Path. Bact., 46, 521-534.

Reich, N. E. (1942). Portal system thrombosis occurring in portal hypertension. Ann. intern. Med., 17, 270-294.

Reynell, P. C. (1951). The prognosis of portal hypertension. Lancet, 2, 383-385.

Rosenthal, N. (1925). Clinical and hematologic studies on Banti's disease. 1. The blood platelet factor with reference to splenectomy. J. Amer. med. Ass., 84, 1887-1891.

Simonds, J. P. (1936). Chronic occlusion of the portal vein. Arch. Surg. (Chicago), 33, 397-424.

Simmonds, M. (1912). Über Pfortadersklerose. Virchows Arch. path. Anat., 207, 360-373.

Warthin, A. S. (1910). The relation of thrombophlebitis of the portal and splenic veins to splenic anaemia and Banti's disease Int. Clin., 20th ser., 4, 189-226. 